\title{
XI. Observations on platina, and its utility in the arts, together with some remarks on the advantages which reflecting have over achromatic telescopes
}

\section{Alexis Rochon}

To cite this article: Alexis Rochon (1798) XI. Observations on platina, and its utility in the arts, together with some remarks on the advantages which reflecting have over achromatic telescopes, Philosophical Magazine Series 1, 2:6, 170-177, DOI: $10.1080 / 14786449808676901$

To link to this article: http://dx.doi.org/10.1080/14786449808676901

\section{Published online: 18 May 2009.}

\section{Submit your article to this journal $\sqsubset$}

\section{山ll Article views: 3}


the chafe. A tenth part of the dogs ufed were not wolfdogs, which never were in any number in the hands of the common peoples I conceive alfo, that thefe dogs having no no/e, other kinds were neceffary to find the game and follow the fcent of it. Scahil defcribed wolves with fuch perfect accuracy, that I have no doubt of his being well acquainted with the animal."

XI. Obfervations on Platina, and its Utility in tbe Arts, together witb fome Remarks on the Advantages wbich reflecting bave over acbromatic Telefoopes. By ALExis Rochon, Director of the Marine Obfervatory at Breft. From the Journal de Phyfique, 1798.

[Concluded from page 27.]

\section{FORGED PLATINA.}

\section{$\mathrm{T}$}

$\mathrm{HE}$ reader muft recollect that all metals are eafily melted after they have been reduced into very thin plates. Thus gold leaf melts at the flame of a taper, though not excited by a blow-pipe. In this manner alfo philofophers are enabled to melt thofe fmall glafs globules which ferve them as fimple microfcopes. This obfervation is fufficient to indicate the procefs that muft be purfued in the operations in regard to forged platina. The platina is firt purified by means of nitre and fandifer ( $\int e l$ de verre) ; this mineral is then divided into very minute particles, either by trituration, or by folution in nitro-muriatic acid or diluted nitric acid, according to the method of my colleague Tillet.

Nitre, antimony, arfenic, and, in fhort, every fubftance which becomes volatilized, may be employed for this operation; but arfenic ought to be preferred, becaufe it is more eafily diffipated. The platina being thus divided into exceedingly fmall particles, muft be expofed to a frong fire, which muft be excited fill more by the oxygen gas that 
direngages itfelf from nitre in combuftion. In this violent fire the particles of the platina become agglutinated ; and by forging them at a white heat repeated times, the workman is able to give them fufficient adhefion to ftand being hammered into plates. The well-known labours of Sickengen on forged and laminated platina render it unneceffary to fay any thing further on this fubject. He allowed me to fee his procefs; and to that favour 1 am indebted for the knowledge neceffary to enable me to treat a difficult fubject abfolutely foreign to my ftudies.

\section{CAST PLATINA.}

Caft platina is infinitely more interefting to the arts ; and it is on this labour that I have beftowed my chief attention. The procefs which perfectly fucceeded with me, to caft crucibles and large pieces of platina of different forms, was, to melt the metal according to the method of Scheffer, by a mixture of arfenic and fandifer. The fre muft be moderate; and for this reafon there muft be at leaft ten pounds of arfenic and four pounds of fandifer to melt one pound of platina. The mafs then will be in a ftate of perfect fluidity when poured into the mould, though the fire be fcarcely fufficient to fufe filver. Platina in this ftate is exceedingly fragile and brittle; were it expofed to a red heat, the operation would abfolutely mifcarry. The arfenic, by difengaging itfelf too rapidly, would reduce it to fcales, which would no longer have any adhefion. It may readily be conceived, that this accident muft have occurred to me more than once. I have, however, been able to awoid it by enclofing the pieces of platina which I had moulded in a box of plate-iron, filled with fand and pounded charcoal. I then expofed them for more than a month to a fire graduated from the heat of boiling water to that which fufes flver. Platina in this ftate no longer refembles a metal : it might rather be taken for a metallic calx. The particles which 
compofe it are very clofe; but they have only a very feeble adhefion, like that of an earthen veffel dried in the thade. It is then that the platina muft be expofed to the moft violent fire; and when the metal has undergone that operation it refumes its natural ftate, becomes fonorous, malleable, and the frongeft heat gives it always new degrees of improvement.

A little time after I had read this memoir, the learned $\mathrm{Dr}$. Ingenhouz begiged me to unite into a mafs for him about two ounces of platina, which he $k_{t}$ ad carefully purified by means of the nitro-muriatic acid. I was obliged to enclofe in a very thin leaf of platina all the fragments of this metal, which were too fcattered and too minute to be fubjected feparately to the action of the fre and of the ftamper; but, when thus united, I gave them the higheft degree of. heat poffible to be produced from charcoal excited by a pair of bellows; and I foon obtained, by friking them with the ftamper, a ductile and malleable mafs. After the fuccefs of this experiment, I employed myfelf in purifying in the fire, and in a crucible, platina in grains, by means of nitre and fandifer, which muft be afterwards wafhed in the nitric acid; and by ftriking at a white heat thofe grains contained in the laminæ of platina, I procured at a fmall expense confiderable maffes of malleable platina. This procefs will render unneceffary hereafter the ufe of the oxyd of arfenic, unlefs the workman withes to obtain, by cafting, large crucibles or muffles of platina.

$I$ was the firft who treated platina in a large mafs in a manner truly ufeful to the arts : and though I have paid a great deal of attention to this labour, affifted by the information of the learned Ifquierdo and the metallurgic talents of Daumy junior, I bave employed my chief care in improving the mixture of platina with tin and the oxyd of arfenic, for the conftruction of large fpecula for telefcopes, and, above all, for the fpecula of fextants and other inftruments for de- 
cermining the longitude at fea. In the latter labour I have been well feconded by Carrochez and other artifts who worked under my direction.

Being fully fatisfied with the trials, of which I have given an account in the preceding memoir, I was defirous of conftructing a telefcope like that of Herfchel. For this purpore, I engaged in the year 1790 a friend of the arts and fciences, the unfortunate Trudaine junior, to procure from Herfchel a good feven-feet telefcope. The fuperiority of the telefcopes made by that able aftronomer depends much more than generally believed on the Newtonian conftruction which he has adopted. The Gregorian telefcopes are by to means to be compared to the former. An appearance of convenience made them however to be commonly adopted, though that conftruaion prefents great difficulties to be furmounted in the complete execution of it. But as it is always neceffary in the ufe of telefcopes, the magnifying powers of which are confiderable, to adapt a magnifier that embraces a wide field, in order to find readily in the heavens the ftar to be obferved, it may eafily be perceived that it is a matter of indifference whether the telefcope employed for that purpofe he of the Gregorian or Newtonian confruction ; becaufe in that cafe a direct or lateral view of the object is abfolutely indifferent. The lateral fight is indeed much more convenient when the Newtonian telefcope is well difpofed on its ftand. Herfchel has adopted for his telefcopes a conftruction ftill more ancient and fimple; and though it approaches near to the origin of the art, it is no lefs ufeful when ufed for large inftruments. I have admired the effects of it in his telefcope of twenty feet; and I hould have been enabled to form a better judgment of it in that of forty feet, but there then ftill remained fome improvement to be made in the latter, which is unique in the annals of aftronomy. It is certain that a fmall inclination given to a concave mirror of a long focus does not fenfibly disfigure the image formed in its focus. This fmall inclination is fufficient to permit the obferver to look through a ftrong magnifier at the image 
of the ftar, without intercepting, by the head, the rays which proceed from it.

In the beginning of the year 1791 , Trudaine entrufted to me the telefcope which be had procured at London. Aftronomy is indebted to Herfchel for the nobleft difcoveries of this century. The name of that obferver will be tranfmitted to the moft diftant ages. He has augmented our planetary fyftem, and enriched it with a new planet, accompanied with feveral fatellites. In 1671, Dominic Caffini, obferving the moon with an excellent telefcope of Campani, remarked in the obfcure part of her, fome fmall whitifh nebula. This interefting phenomenon did not efcape the telefcopes of Herfchel; and after the year 1784 , that able aftronomer announced, that he had feen a burning volcano in the middle of the fpot called Ariftarcbus. We find in the Memoirs of the Academy of Sciences for the year 1706 the following remarkable paffage of De la Hire: "The fmall fpot of Ariftarchus is fo brilliant, that fome have believed it to be a volcano."

Are thefe fmall whitith nebula bodies luminous of themfelves, or do they enjoy only a horrowed light? Such is the queftion which I propofed to refolve, by affiduondy obferving thefe fmall nebula, both with Herfchel's telefcope, and that which I caufed to be conftructed of platina in the courfe of the year 1791 , on the model of that of the above aftronomer. Being deprived, fince September 1792, of the ufe of that inftrument ${ }^{*}$, the conftruction of which had colt me great

* Telescopes of still greater maynifying powers $m$ 'ght be so easily procured at Paris, that those who dre truly interested in the progress of the arts and sciences are not a little astonished that the great telescope of sixty feet, announced in all our journals, is still a project; and that no one even so muchas thinks of realizing it. Though the art of making large specula is attended with some difficulties, it however requires neither the same talents nor the same patience as that of constructing large achromaticobject glasses. The catoptric telescope requires only the regular labour of a single surface, and it is the work of a few moments which forms or deforms the polish of the concave surface of a large speculum. 
labour and much money, I was not able to continue this kind of obfervations.

This telefcope of feven feet, which I confider as fuperior to that of Herfchel of the fame length, enabled me, during the time $I$ had the ufe of it, to be convinced that the fpot Ariftarchus, if not a volcano, is at leaft a body luminous of itfelf. The grounds on which I found my opinion are agree. able to the principles explained by Bonguer in his Treatife on the Gradation of Light ; for thofe fpots of the moon which reflect moft ftrongly the direet light of the fun did not exhibit to me in the fhade the fame appearances as Arif tarchus, whatever efforts I made to augment the intenfity of that feeble light which arifes from the reflected rays of the earth. Befides, it is eafy to conceive that a very lively fire, concentrated in the hollow of a crater, cannot diffe. minate the light which emanates from it: in that particular cale, like a reverberator, it cannot be feen but under certain circumftances. It is remarked then, that it is in the months of Pluviofe, Ventofe and Germinal that this volcano is moft apparent.

When I undertook a journey to London, by order of Government, for the benefit of the fciences, I employed myfelf in a particular manner in the improvement of flint glafs; and I was convinced that the propereft and fimpleft means for rendering flint glafs fit for conftueting large achromatic telefcopes confint in removing the threads by means of a glafs-cutter's wheel. When thefe faults are removed, the glars is to be kneaded in an oven and under a muffle, in fuch a manner as to give it almolt the form and fize of the object-glafs required to be made. This procefs is amply defcribed in my work entiled Recusil de Memoires fur lo Mecbanique st la Pby/ique.

It was in this collection that I faid that Euler had been the firft who thought of correcting the aberrations of refrangibility by ufing fubstances of different refractive powers. Maupertius engaged to get confructed at Paris Eu- 
Jer's object-glafs, with water and glafs like that which Newton had imagined, to render the aberration of fphericity as little as poffible; but this object-glafs did not fucceed, on account of the proportion ince known between the refraction and difperfion of common glafs and water. This proportion is by the diafporameter as 155 to 133 in regard to refraction, and as 100 to 67 in regard to difperfion. But the ftrong curvatures which muft be given to deftroy the aberration of refrangibility would occdion a very ftrong aberration of fphericity. Thus, what might be gained on one hand would be infallibly loft on the other. This was fufficient to make Euler's project mifcarry, and to confirm the affertion of Newton, which tended to defroy all hope of being able to obtain achromatifm in glafs. Since that epoch the firft knowledge of the ftrong difperfion of glafs in the compofition of which there is much laad, and which in England is known under the name of fint gla $/ s$, has been afcribed to John Dollond. This appellation however is not that beft fuited to this kind of glafs. But what is of moft importance to be known here is, that the more lead, or rather minium, is employed in making glafs, the more will its difperfive power be augmented. It was in the year 1759 that Dollond prefented achronatic glaffes, compofed of flint and crown glafs. He fays in his paper printed in the Philofophical Tranfactions, that he found means to deftroy with great eafe the aberrations of refrangibility; but he confeffes that he was fopped by an object more difficult to be furmounted, that of annihilating at the fame time the aberration of fphericity. It was thought, and is fill believed in France, that John Dollond was the inventor of achromatic telefcopes; but we know that, fome years after, Dollond's patent was attacked, on the ground that he was not really the inventor*.

XII. $A$

- The author heregoes on to give what he considers a cor et account of the origin of the invention; but as hets incorrect in almost every cir- 
ctmstance, we suppress the rest of his paper, and subjoin an article on the subject which appeared in the Gentleman's Magazine for October 1790 , and which, we have been in formed by Mr. Ramsden, contains a true statement of the facts:

" The inventor was Chester More Hall, Esq. of More Hall, in Esser, who about 1799, as appears by his papers, considering the different humours of the eye, imagined they were placed soas to correct the different refrangibility of light. He then conceived, that it he could find substances haviny such properties as he supposed these humours might possess, he should be enabled to construct an object-glass that would show objects colourless. After many experiments, he had the good fortune to find these properties in two different sorts of glass; and by forming lenses made with such glass, and making them disperse the rays of light in contrary directions, he succeedecl. About 1783 he completed several achromatic object glasses (though he did not give them that name) which bore an aperture of more than $2 \frac{1}{2}$ inches, though the focal length did not exceed 20 inches; one of which is now in the possession of the Rev. Mr. Smith, of Charlotte-street Pathbone-place. This glass has been examined by several gentlemen of eminence and scientific abilities, and found to possess the properties of the present achromatic ylasses.

"Mr. Fiall used to employ working opticians to grind his lenses ; at the same time he furnished them with the radii of the surfaces, not enly to correct the different 1 efrangibility of rays, but also the aberration arising from the spherical figures of lenses. OH Mr. Bass, who at that time lived in Bridewell Precinct, was one of these working opticians, from whom Mr. Hall's invention seems to have been obtained.

"In the trial at Westminster-hall about the patent for making achromatic telescopes, Mr. Hall was allowed to be the inventor; but Lord Mansfield observed, that "it was not the ferson who locked up his invention in his scrutoire that ought to profit by a patent for such invention, but he who brought it forth for the benefit of the public." This, perhaps, might be said with some degree of justice, as Mr. Hall was a grentleman of property, and did not look to any pecuniary advantage fiom his discovery; and consequently, it is very probable that he might not have an intention to make it generally known at that time.

"That Mr. Ayscough, optician on Ludgate-hill, was in possession of one of Mr. Hall's achromatic telescopes in 1754, is a fact which at lis time will not be disputed."

VOL. II, 